\title{
Understanding the genetically at risk: clinical, psychological and social approaches
}

\author{
LYN TURNEY ${ }^{1}$
}

\begin{abstract}
The scientific discovery of a range of genetic mutations has meant that people with a strong family history of cancer can find out whether they are at risk of developing cancer well before they have any symptoms. Genetic testing has opened up the possibility for otherwise healthy mutation carriers to access prophylactic treatments in order to minimise their risk. These include surgery to remove at-risk body parts, treatment with cancer drugs, medical surveillance strategies, self-surveillance and change in lifestyle. Clinical experience to date has shown considerable resistance to the uptake of medical preventative measures despite their promise of risk reduction. This paper provides a summary review of the available literature on the medical, psychological, counselling and social aspects of genetic testing and the use of riskreducing treatments by people who have been diagnosed with a genetic predisposition to cancer. It acknowledges what has been learned from these approaches but points to the similarity of the philosophical underpinnings of most of the research. It concludes by tentatively making some suggestions, informed by the literature, about new directions for guiding our understanding the genetically at risk and the factors that influence their decision-making.
\end{abstract}

\section{Introduction}

The discovery of a range of genetic mutations has meant that people with a strong family history of cancer can find out whether they are at risk of developing cancer well before they have any symptoms. ${ }^{2}$ Testing can determine if an individual is more susceptible than others in the population to developing the cancer. The patterns of cancer onset, however, are not straightforward; for example, in Australia among carriers of the BRCA1 and BRCA2 gene mutations, the cumulative lifetime risk is 5060 per cent for developing breast cancer and 20-40 per cent for ovarian cancer. ${ }^{3}$

Although there is no certainty they will develop cancer, 'at risk' people are offered a range of preventative medical risk management options which themselves are potentially harmful. For example, meta-analyses of studies on carriers of BRCA1 and BRAC2 have shown post-operative psychological and physical morbidity after prophylactic surgery ${ }^{4}$ and a small probability of serious side-effects from chemoprevention, including uterine cancer and death from blood clots. ${ }^{5}$ The most effective medical risk reduction strategy is deemed to be the surgical removal of currently unaffected but cancer-susceptible body parts, such as breasts or ovaries, which can lower the person's risk of getting breast or ovarian cancer to below that of the general population. ${ }^{6}$ Other medical options offered are risk-reducing drug therapy or chemoprevention (involving drugs such as tamoxifen or raloxifine) or surveillance strategies, which include regular radiographic imaging such as mammography, magnetic resonance imaging (MRI), ultrasound (for ovarian surveillance) and regular clinical examination. ${ }^{7}$ Non-medical strategies include routine self-examination and 
attention to lifestyle factors such as weight and diet management, though these are viewed as less than optimal.

For those found to have a genetic predisposition to breast and ovarian cancers, preventative or prophylactic surgery is seen to be the best form of risk management, although not a guaranteed solution, while surveillance techniques are thought to be less successful at early detection, particularly in young women whose denser breast tissue tends to compromise cancer detection by mammography. ${ }^{8}$

According to the medical literature, the discovery of a cancer gene mutation is predictive of cancer; it has no immediate effect on physical health and not all people who have the genetic mutation go on to develop cancer. In particular, people identified with a genetic mutation which is predictive of cancer can be offered preventative treatment. However, clinical experience to date has shown considerable resistance to the uptake of medical preventative measures despite their promise of risk reduction. ${ }^{9}$

The aim of this paper is to provide a summary review of the available literature on the medical, psychological, counselling and social aspects of genetic testing for breast and ovarian cancer and to outline what is known about the use of risk-reducing treatments by people who have been diagnosed with a genetic predisposition to cancer. While there is a wealth of information about the clinical experience of those genetically at risk of cancer and the reasons for the treatment choices they make, an understanding of their decision-making outside of the clinic has been much less explored. This paper reviews the literature around decision-making on medical treatment options, including surgery, drug therapy (chemoprevention) and medical surveillance (MRI, ultrasound and mammography). It also explores literature that moves through phenomenological accounts of the experience of being genetically at risk of disease to the accounts of the broader social changes that might impact on people's health decision-making. While there is much to be learnt from the literature to date, its focus on informed decisionmaking through non-directive counselling in the clinic may overlook factors that contribute to quite active decisions to resist medical treatment that are grounded in the conditions of the lives of people who are genetically at risk of cancer.

\section{Research on those at risk of genetic cancers}

Although genetic testing is available for more than 1000 inherited disorders, most research on genetic cancer predisposition and uptake of treatment options has been conducted on breast and ovarian cancer ${ }^{10}$ because awareness has been raised by institutionalised population screening programmes. Fewer studies have been conducted on people who have a predisposition to other forms of cancer such as bowel and prostate cancers. ${ }^{11}$ This paper will focus on those who are known through genetic testing to carry the BRACA1 and/or the BRCA2 gene mutation/s, though the issues raised are likely to have broader application to those identified with a range of other genetic cancer mutations.

Overall, studies focus mainly on psychological, clinical and counselling aspects of genetic testing, with a smaller but increasing number concerned with the use of risk-

Genomics, Society and Policy, Vol.5, No.2 (2009) ISSN: 1746-5354

(C) ESRC Genomics Network. 
reducing treatments by people who have been diagnosed with a genetic predisposition to cancer. These studies can be divided into three broad but overlapping categories: those that explore attitudes to, or intention to comply with, recommended treatment; ${ }^{12}$ those that have investigated patterns of surveillance behaviours and rates of prophylactic surgery uptake following genetic mutation testing; ${ }^{13}$ and, those that investigate factors contributing to decision-making about treatment options. ${ }^{14} \mathrm{~A}$ further two categories include social science research which focuses on the experience of patients and families coping with a genetic disease itself ${ }^{15}$ and those studies that take a broader socio-cultural approach to the importance of the body in consumer culture and a consumerist approach to risk and risk assessment in relation to the medicine and medical technologies. ${ }^{16}$ Comparatively little is known about how the larger group of mutation carriers who eschew all forms of medical treatment make sense of their risk in the broader context of their lives, the complicated and daunting decisions that they have to make and the reasons why they decide against medical treatment options. ${ }^{17}$

\section{Clinical studies: Levels of treatment uptake and compliance rates}

Most studies report relatively low levels of intention to undergo prophylactic surgeries, with bilateral ovarian removal (salpingo-oophorectomy) much more acceptable to women than breast removal (mastectomy). ${ }^{18}$ When it comes to actual behaviours of carriers of genetic mutations, the patterns of prophylactic surgery and surveillance are similar to studies of intentionality. Claes and colleagues, ${ }^{19}$ in a oneyear follow-up after a mutation positive test, found that 9 per cent of women had had a prophylactic bilateral mastectomy while 75 per cent had had a bilateral oophorectomy. Meijers-Heijboer et al's study of 682 mutation carriers found much higher rates of bilateral mastectomy ( 51 per cent) and oophorectomy ( 64 per cent) in young women aged $30-44 .{ }^{20}$ A smaller study found that a majority of carriers did not choose surgery (only 3 per cent and 13 per cent respectively) but 68 per cent had regular mammography screening. ${ }^{21}$ Similarly, Botkin et al's study showed a zero and 46 per cent uptake rate respectively of surgery and 82 per cent mammography compliance. ${ }^{22}$ Evans and colleagues found that 61 per cent of eligible women opted for MRI screening ${ }^{23}$ while Metcalfe et al reported low levels of chemoprevention uptake (12 per cent tamoxifen and 10 per cent raloxifene). ${ }^{24}$ More recent studies have found variation in the uptake rates of risk-reducing surgery contingent on time from gene test to follow-up, with higher overall rates, especially among younger women who tend to delay bilateral removal of ovaries until family completion. ${ }^{25}$ In addition, variation in uptake depends on country of study, with the United States having the highest rates of prophylactic bilateral mastectomy (36.3 per cent) ${ }^{26}$ A review study examining the evidence for prophylactic treatments pointed out that all these studies are retrospective and short-term follow-up prospective cohort studies that fall well short of the rigour of randomized control trials and thus provide insufficient justification for making irreversible decisions about radical prophylactic treatments. ${ }^{27}$

In summary, rates of uptake of preventative surgery are uneven, indicating that programmes have different levels of success in enrolling the genetically at risk in preventative treatments. Despite this, even those programmes with the highest rates of treatment uptake show a high number of mutation-positive people rejecting 
prophylactic surgery and an even higher number refusing chemoprevention. While surveillance techniques are less efficacious, they appear to be the preferred treatment choice for mutation positive-people who remain under the 'medical gaze'. ${ }^{28}$

\section{Psychological and counselling studies: decision-making around treatment options}

Most studies on people who are genetically at risk of cancer have been undertaken with clinical samples and focus on psychological, clinical and counselling aspects of genetic testing. The majority are from a medical science and psychological perspective and they generally show the benefits to people of knowing and understanding their genetic risk status in relation to cancer. ${ }^{29}$ Perhaps unsurprisingly, given the clinical setting of the studies, they also show that predictive genetic testing itself does not necessarily have major adverse psychological outcomes. ${ }^{30}$ On the other hand, studies on familial genetic testing show that a substantial number of first-degree relatives, who are likely to receive their information in a non-clinical context, do not follow up offers to find out about cancer mutation status and do not adhere to surveillance guidelines. ${ }^{31}$ A subsection of these studies investigate factors that contribute to decision-making around risk-reducing treatment options. Reasons given for non-uptake of preventative measures are reported to be related to personality factors such as 'psychological vulnerability' and 'psychological functioning,' including feelings of guilt about having and passing on a defective gene, and distress, anxiety and depression during and after genetic testing. ${ }^{32}$

In terms of understanding why people opt for prophylactic treatment, anxiety about cancer risk itself has been found to be more likely to motivate women to seek prophylactic bilateral mastectomy than actual level of risk. ${ }^{33}$ Counselling studies also focus on ways of reducing 'cancer worry' and improving information provision about risk, something that is often quite complex to convey in lay terms. The effectiveness of risk communication has also been assessed, with studies showing that perception of risk is more accurate after counselling, and that individual differences as well as variation in social and environmental factors need to be taken into consideration. ${ }^{34}$ Genetic counselling focuses on interpretation of risk factors, education about 'inheritance, testing, management, prevention, resources and research', and counselling to promote informed choice about treatment options. ${ }^{35}$ These, though, are all traditional medical options: surgery, drugs, or surveillance technologies that can be provided in the clinic. Mandated genetic counselling is itself underpinned by an assumption that health decisions are made on the basis of objective knowledge about risk and treatment options. In this view, rejection of medical treatment is seen to be based on a 'knowledge deficit' which can be rectified, and acceptability increased, with education and the dissemination of accurate and objective information. ${ }^{36}$ While the client-led non-directive genetic counselling model differs significantly from the traditional hierarchical medical model in terms of informed and autonomous decisionmaking, the range of options from which a decision is to be reached remain medical alternatives. Although immediate familial contexts are taken into consideration in the counselling model, the broader socio-cultural factors that may contribute to decisionmaking are not. 
The focus on individual psychological morbidity and its relief through effective counselling overlooks both the overwhelming nature of the information itself and normality of people's responses to it. It also overlooks some of the more complex responses that gene mutation carriers might have. Butow and her colleagues refer to individual responses as "somatic distress", ${ }^{37}$ promising to extend analysis beyond an examination of behavioural responses to the embodied experience of being identified as a mutation carrier. While this approach implies a more complex visceral process, around the embodied experience of being genetically at risk, it is left unexplained. However, Barsky provides an explanation of somatic symptoms which seems to imply a condition otherwise known as 'anxiety' or 'panic attack,' wherein the sufferer has awareness of bodily changes but these are not evidenced upon physical examination. ${ }^{38}$ Similarly, other studies point to (but do not expand on) factors such as 'emotional responses' that impact on levels of 'cancer worry'. ${ }^{39}$ Several clinical studies have sought to understand the emotional impact on women who have undergone prophylactic surgery to eliminate cancer risk. ${ }^{40}$ Those who opted for surgical methods reported more distress about their mutation carrier status than those who decided on medical surveillance and, in both the short and longer term, although their cancer risk worry was significantly reduced, their level of anxiety remained higher than for the surveillance group. ${ }^{41}$ In other words, predictive genetic knowledge appears to be more worrisome for those with a propensity towards anxiety in general.

\section{Social science approaches: The experience of being genetically at risk}

Most of the phenomenological research into meaning making from a patient perspective focuses on patients' and families' experiences of coping with a genetic disease itself. ${ }^{42}$ These studies engage with lay models of genetic inheritance and provide contextual explanations for understanding how people make sense of the multifactoral nature of genetic disease causation. ${ }^{43}$ While they provide important insights into the life-worlds of at-risk individuals, these experiential studies generally maintain the clinical focus of the medical, psychological and counselling approaches. The experiential dimension, by necessity, contextualizes the individual within the clinic which, as Kerr argues, tends to invoke and reinforce the passive and dependent patient role of traditional biomedicine, while positioning healthy mutation carriers and other pre-symptomatic family members as patients 'waiting to become ill'. ${ }^{4}$

Other studies report on lay understandings of genetic inheritance and how people make sense of their own genetic risk through a range of heuristic strategies, family storytelling and interpretation of risk factors according to emotional and age closeness to a cancer affected relative. ${ }^{45}$ In those who had a positive test result, familial risk itself was found to be mediated by strong moral notions of responsibility to the family to inform and disseminate information about carrier status and of 'doing the right thing' in relation to compliance with treatment regimens. ${ }^{46}$ Disclosure of risk was also reported to be a gendered responsibility falling disproportionally on women. ${ }^{47}$ Other studies on genetic risk focus on how people's perceptions of risk change over time and become more or less salient at different stages of their lives. ${ }^{48}$ Some of these studies make parallels between living with the knowledge of being genetically at risk of disease and the experience of living with a chronic illness. Despite the uncertainty 
around genetic status for those with a family history of cancer and those for whom the genetic test is not definitive, they report that being at-risk of genetic disease has a similar impact on self identity as does having chronic illness. It is experienced as 'biographical disruption' or a profound disturbance in one's sense of self, one's place in the world and one's relationship to others. ${ }^{49}$ Even though most of these studies provide important insight into the experience of genetic risk and position the at-risk individual in the context of their immediate familial and social interactions, they remain conceptually aligned with the genre of clinic-based studies that tend to exaggerate the place of risk in people's lives. ${ }^{50}$ By locating their experience in the potentiality of biological risks, rather than in the broader structural conditions of their lives, they give only partial perspective on the individual experience of hereditary cancer risk.

\section{The wider socio-cultural context of predictive genetic testing}

Recent risk studies link individual risk and risk awareness to the sociological literature on 'risk society' and a generalised appreciation of the multifarious sources of danger and risk in contemporary life that are seen to threaten health and safety, of which genetic risk is one. ${ }^{51}$ Genetic risk communication itself solidifies for individuals and their families otherwise quiescent health risks which potentially threaten everyone, given the multitude of mutations that may exist in a family's gene pool. ${ }^{52}$ Engagement with the discourse of the genetic clinic, which constructs mutation carriers as responsible for managing their own health risks, not only heightens risk awareness but also the burden of genetic knowledge. ${ }^{53}$ The genetically at risk are charged with the duty to acquire genetic risk information as well as to disseminate and communicate risk status to family members. ${ }^{54}$ The burden of genetic knowledge extends also to those with familial risk even where a test outcome is inconclusive, because disease-free individuals who remain uncertain about their mutation status are left to engage in a range of regular, ongoing and precautionary medical surveillance activities ${ }^{55}$ Once diagnosed with a genetic mutation, carriers take on the collective fear of cancer and, though they are still cancer free, the threat becomes immanent and they may want to have removed the potentially affected body part, which is now recast as dangerous. ${ }^{56}$ Discursively, there is a broader moral and social imperative to engage in curative, preventative actions which may be more dangerous and disfiguring than the potential disease they seek to eliminate. ${ }^{57}$

In their study of the genetically at risk for ovarian cancer, Hallowell and Lawton found that, while the decision to undergo prophylactic surgery provided participants with a sense of agency to achieve a risk-free body, the removal of (healthy) ovaries as a 'cure' also incurred emotional, material and interpersonal losses to identity, body and sense of self. ${ }^{58}$ In one clinical study, researchers asked women about body image and intimate relationships following prophylactic mastectomy or oophorectomy. ${ }^{59}$ They found that surgery could have serious negative outcomes for a woman's self image, self esteem and physical and emotional well-being. While it seems to be the best option from a clinical viewpoint, prophylactic mastectomy is the least acceptable for women themselves. ${ }^{60}$ Seen in socio-cultural context, the centrality of the body and its exteriority have become important to self definitions and expressions of the self, so 
radical surgery and its side-effects challenge body image, feelings of well-being, personal identity, and sexual relationships. ${ }^{61}$

Much research consistently overlooks the substantial changes that have occurred in patterns of health consumption, including the pre-eminence given to having a healthy body. In contemporary consumer culture, continual efforts are made by individuals to maintain, shape and perfect the body through routines of diet, exercise and preservation of well-being that go beyond simply being healthy. ${ }^{62}$ The body has thus become a key site of vigilance through self-surveillance and self-care. ${ }^{63}$ But this activity is confounded by knowledge of the embodied self as the at-risk mutation carrier who is potentially unhealthy. Having an inherited predisposition to cancer is at odds with the hitherto exterior, experiential and healthy body. Within a medical framework, the genetically at risk are expected to consume treatments that interrupt their continual and ongoing body work. What this means is that, rather than simply being non-compliant or resisting medical intervention, those at risk of disease may actively and rationally choose not to engage in prophylactic treatment measures.

The $21^{\text {st }}$ century has seen the emergence of a new, informed medical consumer who has greater access to health information through the internet and the bombardment of public health messages. ${ }^{64}$ This informed medical consumer is empowered to enter the clinical encounter largely on her own terms, thus deconstructing the traditional 'passive patient' role, which was characterized by unquestioned practitioner authority over patients. ${ }^{65}$ In the context of predictive genetic testing, the client (who is not a physically sick patient) is defined as suitable for certain medically prescribed preventative treatment measures. While the traditional 'doctor knows best' idea absolved the patient from responsibility for illness and its management, the ideas of self-care and health maintenance now make the lay person, rather than the professional, responsible for health decision-making. ${ }^{66}$ This has resulted in the coconstruction of new dialogue between doctor and patient in which the patient/consumer seeks to maximize the value of medical services by actively engaging with, assessing and challenging expert medical knowledge, while consuming or rejecting medical services. ${ }^{67}$ What this may mean is that, for the genetically at risk, the decision not to engage with medical treatment options, may very well be an active and informed choice rather than non-compliance or a failure to understand the benefits of prophylactic measures.

Additionally, given the low client acceptability of prophylactic surgery and chemoprevention $^{68}$ and the low sensitivity of the test, which detects only 25 per cent of those mutations with a hereditary basis, Boenick ${ }^{69}$ suggests that genetic testing should first be carried out on already ill or symptomatic women and only after mutation status is identified as familial should testing be offered to non-symptomatic family members. This would narrow the target population and increase the predictability of the test, thus avoiding the burden on healthy individuals who do not have a definitive test outcome and are left with having to engage in a range of ongoing and precautionary medical surveillance activities. 
A more positive view of health consumer choice in the face of genetic knowledge is put forward by Novas and Rose, who argue that the new genetics has seen "the reshaping of personhood," with the genetically at risk assuming responsibility and achieving their full potential within "new communities of obligation and identification". ${ }^{70}$ From their study, they contend that people who are genetically at risk do not simply accept genetic diagnoses as constitutive of their entire identity. Rather, they develop strategies that make sense in their lives at any particular time. In the context of people's everyday lives, negative responses to being at risk can be subverted and actively resisted. Genetic diagnoses therefore need to be understood in collective contexts where family, social and cultural responses can and do shape interpretations in a multiplicity of ways. ${ }^{71}$

Broader socio-cultural approaches demonstrate both the complexities and uncertainty of predictive genetic testing and the decision-making processes faced by those known to carry a genetic mutation that puts them at risk of cancer. They open up the possibility of understanding the genetically at-risk from a different stance from the clinical, by assessing the individual and social acceptability of predictive genetic testing and treatment based on probabilistic information. Although some of these studies were conducted within clinical settings, they are philosophically informed by a paradigm that takes understanding outside a purely medical framework. A medical paradigm is underpinned by assumptions that limit the possibility of better understanding the motivations and decision-making processes of those who are genetically at risk. In particular, medical, clinical and counselling, as well as some social, research operates within the closed conceptual system of traditional biomedicine wherein the discovery of disease is followed by a curative intervention. So, once a mutation (or even its possibility) is identified, the option of not taking up treatment is foreclosed even if the gene has not expressed and the person is cancer free.

The final conceptual hurdle to an appreciation of the dynamics of consumer understanding and use of predicative genetic testing and consequent (non)uptake of medical treatment options rests with the epochal change in the nature of medical practice itself, from curative to predictive medicine. ${ }^{72}$ A new era in the history of medical practice has heralded a move from certainty about health and illness and curing sick bodies to the prediction of illness and probability of future disease. While the shift from curative to predictive medicine has been made at a conceptual level, clinical practitioners remain caught within the curative model when it comes to acting upon predictive information. There is a mismatch between what is known about health and disease and what can be done about it. On the one hand, clinicians have extremely sophisticated techniques to identify potential disease at a molecular level, providing information that might lead to preventative measures to promote health and wellbeing. On the other, currently available treatment options are borrowed from curative medicine and are somewhat blunt instruments for dealing with healthy bodies potentially at risk of cancer.

These theoretical constructs highlight the need to explore consumer acceptability of medical treatment in the context of differential understandings of the healthy body;

Genomics, Society and Policy, Vol.5, No.2 (2009) ISSN: 1746-5354

(C) ESRC Genomics Network. 
that is the healthy, 'lived' and somatic or experienced body versus the body deemed to be medically healthy (cancer-free or cancer-risk minimised). Future research needs to take as a starting point an understanding that the subjective perceptions of those genetically at risk are likely to be based on their active engagement with a complex social world and a broader matrix of social relations. Such an approach opens up the possibility of exploring the cultural, personal, historical and social factors that contribute to the ways in which the genetically at risk understand, engage with and resist knowledge about genetic risk. Furthermore, understanding quality of life issues from the perspective of those genetically at risk will inform ways by which predictive genetic knowledge can be better used in the service of preventative healthcare. The World Health Organisation, in its promotion of positive health and the pursuit of wellness, counsels the "appropriate" use of technologies. Best practice strategies for testing and treatment need to evaluate the ethical and psychosocial issues against the benefits of the risk-reduction treatments of traditional biomedicine. Finally, the high economic cost of genetic testing, genetic counselling and medical prevention options necessitates a thorough understanding of individual, family and population opinions and needs in relation to predictive genetic testing.

\section{Acknowledgements}

The author would like to thank the anonymous reviewers for their very useful comments and suggestions. 


\section{References}

${ }^{1}$ Faculty of Life and Social Sciences, Swinburne University of Technology, Victoria, Australia. lturney@swin.edu.au

${ }^{2}$ A strong family history of cancer is defined as having a first or second degree relative who has had cancer.

${ }^{3}$ G.K. Suthers. Cancer risks for Australian women with a BRCA1 or a BRCA2 mutation. ANZ Journal of Surgery 2007; 77: 314-319. This study used age specific relative risk data from a large North American study in combination with Australian baseline incidence data to estimate lifetime cumulative risk. The baseline incidence of breast cancer is higher in North America. See, S. Chen, et al. Characterization of BRCA1 and BRCA2 Mutations in a Large United States Sample. Journal of Clinical Oncology, 2006. 24(6): 863-871.

${ }^{4}$ R. Calderon-Margalit and O. Paltiel, Prevention of breast cancer in women who carry BRCA1 or BRCA2 mutations: A critical review of the literature. International Journal of Cancer, 2004; 112 (3): 357-364; M. Fatouros, G. Baltoyiannis and D. Roukos. The predominant role of surgery in the prevention and new trends in the surgical treatment of women with BRCA1/2 Mutations. Annals of Surgical Oncology 2008; 15(1): 21-33; L. Lostumbo et al. 2004. Prophylactic mastectomy for the prevention of breast cancer. Cochrane Database of Systematic Reviews 2004. Baltimore, MD, USA. The Cochrane Collaboration.

${ }^{5}$ J. Cuzick et al. First results from the International Breast Cancer Intervention Study (IBIS-I): a randomised prevention trial. Lancet 2002; 360(9336): 817-824.

${ }^{6}$ Suthers, op. cit. note 3; K.M. Field and K.A. Phillips. Management of women at high familial risk for breast and ovarian cancer. Cancer Forum 2007; 31(3): 141-149; Calderon-Margalit and Paltiel, op. cit. note 4; Fatouros, et al., op. cit. note 4.

${ }^{7}$ Ibid; Field and Phillips.

${ }^{8}$ B.O. Anderson. Prophylactic surgery to reduce breast cancer risk: A brief literature review. The Breast Journal 2001; 7(5): 321-330; B. Leggett. Management of high genetic risk of bowel cancer. Cancer Forum 2007; 31(3): 149-153.

${ }^{9}$ J.R. Botkin et al. Genetic testing for a BRCA1 mutation: Prophylactic surgery and screening behavior in women 2 years post testing. American Journal of Medical Genetics 2003; 118(3): 201-209; Field and Phillips, op. cit. note 6, pp. 141-149; C. Lerman et al. Prophylactic surgery decisions and surveillance practices one year fllowing BRCA1/2 testing. The Journal of the American Medical Association 2000; 31(1): 75-80; K.A. Metcalfe et al. The use of preventative measures among healthy women who carry a BRCA1 or BRCA2 mutation. Familial Cancer 2005; 4(2): 97-103.

${ }^{10}$ T.A. Beery and J.K. Williams. Risk reduction and health promotion behaviours following genetic testing for adult-onset disorders. Genetic Testing 2007; 11(2): 111-123.

${ }^{11}$ A.Y Kinney et al. Attitudes toward genetic testing in patients with colorectal cancer. Cancer Practice 2000; 8(4): 178-186; C. Wong et al. Value of database linkage: are patients at risk of familial colorectal cancer being referred for genetic counselling and testing? Internal Medicine Journal 2008; 38(5): 328333; G.M. Petersen et al. Attitudes toward colon cancer gene testing: Survey of relatives of colon cancer patients. Cancer Epidemiology Biomarkers \& Prevention 1999; 8: 337-344.

${ }^{12}$ For example: E.T. Matloff et al. What would you do? Specialists' perspectives on cancer genetic testing, prophylactic surgery, and insurance discrimination. Journal of Clinical Oncology 2000; 18(12): 2484-2492; M. Stefanek et al. Bilateral prophylactic mastectomy decision making: A vignette study. Preventive Medicine 1999; 29(3): 216-221; B. Meiser et al. Intention to undergo prophylactic bilateral mastectomy in women at increased risk of developing hereditary breast cancer. Journal of Clinical Oncology 2000; 18(11): 2250-2257; P. Bennett et al. The impact of breast cancer genetic risk assessment on intentions to perform cancer surveillance behaviours. Journal of Genetic Counseling 2007; 16: 617-623.

${ }^{13}$ For example: Lerman et al., op. cit. note 9 pp. 75-80; Beery and Williams, op. cit. note 10, pp. 111123; J.R. Botkin et al. Genetic testing for a BRCA1 mutation: Prophylactic surgery and screening 
behavior in women 2 years post testing. American Journal of Medical Genetics 2003; 118A(3): 201209; E. Claes et al. Surveillance behavior and prophylactic surgery after predictive testing for hereditary breast/ovarian cancer. Behavioral Medicine 2005; 31(3): 93-105; D.G.R. Evans et al. Uptake of screening and prevention in women at very high risk of breast cancer. The Lancet 2001; 358(9285): 889-891; E.J. Meijers-Heijboer et al. Presymptomatic DNA testing and prophylactic surgery in families with a BRCA1 or BRCA2 mutation. The Lancet 2000; 355: 2015-2020.

${ }^{14}$ For example: Anderson, op.cit. note 8, pp.231-220; N. Hallowell. Doing the right thing: Genetic risk and responsibility. Sociology of Health \& Illness 1999; 21(5): 597-621; M. McAllister. Personal theories of inheritance, coping strategies, risk perception and engagement in hereditary non-polyposis colon cancer families offered genetic testing. Clinical Genetics 2003; 64(3): 179-189; F.M. Walter et al. Lay understanding of familial risk of common chronic diseases: A systematic review and synthesis of qualitative research. Annals of Family Medicine 2004; 2(6): 583-594.

${ }^{15}$ For example: E. Chapman. The social and ethical implications of changing medical technologies: the views of people living with genetic conditions. Journal of Health Psychology 2002; 7(2): 195-206; S. Cox and W. McKellin. 1999. There's this thing in our family: predictive testing and the construction of risk for Huntington's disease. In Sociological Perspectives on the New Genetics. P. Conrad and P. Gabe, eds. Oxford. Blackwell Publishers: 121-145; N. Hallowell et al. Balancing autonomy and responsibility: the ethics of generating and disclosing genetic information. Journal of Medical Ethics 2003; 29(2): 74; N. Hallowell et al. Surveillance or surgery? A description of the factors that influence high risk premenopausal women's decisions about prophylactic oophorectomy. Journal of Medical Genetics 2001; 38(10): 683-691; A. Stockdale. Waiting for the cure: mapping the social relations of human gene therapy research. Sociology of Health \& Illness 1999; 21(5): 579.

${ }^{16}$ For example: N. Hallowell. 'You don't want to lose your ovaries because you think 'I might become a man' '. Women's perceptions of prophylactic surgery as a cancer risk management option. PsychoOncology 1998; 7(3): 263-275; N. Hallowell. Doing the right thing: genetic risk and responsibility. Sociology of Health \& Illness 1999; 21(5): 597-621; L. d'Agincourt-Canning. Genetic testing for hereditary breast and ovarian cancer: responsibility and choice. Qualitative Health Research 2006; 16(1): 97-118; L. d'Agincourt-Canning. Experiences of genetic risk: disclosure and the gendering of responsibility. Bioethics 2001; 15(3): 231-247. M. Boenick. 2008. Genetic diagnostics for hereditary breast cancer: displacement of uncertainty and responsibility. In Genetics from Laboratory to Society. G. De Vries and K. Horstman, eds. Basingstoke and New York. Palgrave Macmillan: 37-63. C. Novas and N. Rose. Genetic risk and the birth of the individual. Economy and Society 2000; 29(4): 485-513.

${ }^{17}$ Botkin et al, op. cit. note 9, pp.201-209; Lerman et.al, op. cit. note 9, pp.75-80; Metcalfe et al, op. cit., note 9, pp. 97-103.

${ }^{18}$ L.S. Di Prospero et al. Psychosocial issues following a positive result of genetic testing for BRCA1 and BRCA2 mutations: findings from a focus group and a needs-assessment survey. CMAJ: Canadian Medical Association Journal 2001; 164(7): 1005-1009; K.A Metcalfe. International variation in rates of uptake of preventive options in BRCA1 and BRCA2 mutation carriers. International Journal of Cancer 2008; 122 ( 9): 2017-2022.

${ }^{19}$ Claes et al., op. cit. note 13, pp.93-105.

${ }^{20}$ Meijers-Heijboer et al., op. cit. note 13, pp.2015-2020.

${ }^{21}$ Lerman et.al, op. cit. note 9, pp.75-80.

${ }^{22}$ Botkin et al, op. cit. note 9, pp.201-209.

${ }^{23}$ Evans et al., op.cit. note 13, pp.889-891.

${ }^{24}$ Metcalfe et al., op. cit. note 9, pp.97-103.

${ }^{25}$ G.R Evans et al. Uptake of risk-reducing surgery in unaffected women at high risk of breast and ovarian cancer is risk, age, and time dependent. Cancer Epidemiology Biomarkers 2009; 18(8): 23182324.

${ }^{26}$ K.A Metcalfe et al. International variation in rates of uptake of preventive options in BRCA1 and BRCA2 mutation carriers. International Journal of Cancer 2008; 122( 9): 2017-2022.

${ }^{27}$ Calderon-Margalit and Paltiel, op.cit, note 3, pp. 357-364. 
${ }^{28}$ M. Foucault. 1973. The Birth of the Clinic: An Archaeology of Medical Perception. New York: Vintage Books.

${ }^{29}$ Di Prospero, op. cit. note 18 pp.1005-1009; P. Butow et al. Psychological outcomes and risk perception after genetic testing and counselling in breast cancer: a systematic review. Medical Journal of Australia 2003; 178(2): 77-81; J. Lim et al. Short and long term impact of receiving genetic mutation results in women at increased risk for hereditary breast cancer. Journal of Genetic Counseling 2004; 13(2): 115-133; A.O. Geirdal et al. Psychological distress in women with at risk of hereditary breast/ovarian cancer or HNPCC cancers in the absence of demonstrated mutations. Familial Cancer 2005; 4: 121-126.

${ }^{30}$ B. Meiser and J.L. Halliday. What is the impact of genetic counselling in women at increased risk of developing hereditary breast cancer? A meta-analytic review. Social Science \& Medicine 2002; 54(9): 1463.

${ }^{31}$ Anderson, op. cit. note 8, pp. 321-330; L.A. Keogh et al. Uptake of offer to receive genetic information about BRCA1 and BRCA2 mutations in an Australian population-based study. Cancer Epidemiology, Biomarkers \& Prevention 2004; 13(12): 2258-2263.

${ }^{32}$ C.H. Halbert et al. Psychological functioning in African American women at an increased risk of hereditary breast and ovarian cancer. Clinical Genetics 2005; 68(3): 222-227; L. Lodder et al. Men at risk of being a mutation carrier for hereditary breast/ovarian cancer: an exploration of attitudes and psychological functioning during genetic testing. European Journal of Human Genetics 2001; 9(7): 492-500; S.T. Vadaparampil, M. Ropka and M. Stefanek. Measurement of psychological factors associated with genetic testing for hereditary breast, ovarian and colon cancers. Familial Cancer 2005; 4: 195-206.

${ }^{33}$ Meiser, op.cit. note 12, pp. 2250-2257.

${ }^{34}$ B. Meiser and J.L. Halliday. What is the impact of genetic counselling in women at increased risk of developing hereditary breast cancer? A meta-analytic review. Social Science \& Medicine 2002; 54(9): 1463-1470; C. Julian-Reynier et al. Risk communication strategies: state of the art and effectiveness in the context of cancer genetic services. European Journal of Human Genetics 2003; 11: 725-736.

${ }^{35}$ R. Resta et al. A new definition of genetic counseling: National Society of Genetic Counselors' Task Force report. Journal of Genetic Counseling 2006; 15(2): 77-83.

${ }^{36}$ A. Petersen and R. Bunton. 2002. The New Genetics and the Public's Health. London and New York: Routledge; B. Wynne. 1996. Public understanding of science. In Handbook of Science and Technology Studies. S. Jasanoff et al. eds. London. Sage: 44-83.

${ }^{37}$ P. Butow et al. Psychological morbidity in women at increased risk of developing breast cancer: A controlled study. Psycho-Oncology 2005; 14(3): 196-203.

${ }^{38}$ A.J. Barsky. Palpitations, Arrhythmias, and awareness of cardiac activity. Ann Intern Med 2001; 134 : 832-837.

${ }^{39}$ M.A. Price et al. Predictors of cancer worry in unaffected women from high risk breast cancer families: risk perception is not the primary issue. Journal of Genetic Counselling 2007; 16: 635-644.

${ }^{40}$ K.P Tercyak et al. Quality of life after contralateral prophylactic mastectomy in newly diagnosed high-risk breast cancer patients who underwent BRCA1/2 gene testing. Journal of Clinical Oncology 2007; 25(3): p. 285-291; L.N. Lodder et al. One year follow-up of women opting for presymptomatic testing for BRCA1 and BRCA2: Emotional impact of the test outcome and decisions on risk management (surveillance or prophylactic surgery). Breast Cancer Research and Treatment 2002; 73(2): p. 97-112; I. van Oostrom et al. A prospective study of the impact of genetic susceptibility testing for BRCA1/2 or HNPCC on family relationships. Psycho-Oncology 2007; 16(4): p. 320-328; Meiser, op. cit. note 12, pp. 2250-2257.

${ }^{41}$ Ibid; Lodder et al.

${ }^{42}$ Chapman, op. cit. note 15, pp.195-206; Cox and McKellin, op. cit. note 15, pp.121-145; Stockdale, op. cit. note 15, pp, 579-596; K. Finkler. 2000. Experiencing the New Genetics. Family and Kinship on the Medical Frontier. Philadelphia: University of Philadelphia Press; N. Hallowell and M. Richards. Understanding life's lottery: an evaluation of studies of genetic risk awareness. Journal of Health 
Psychology 1997; 2(1): 31-43; K. Lowton and J. Gabe. Life on slippery slope: perception of health with cystic fibrosis. Sociology of Health \& Illness 2003; 25(4): 289-319.

${ }^{43}$ McAllister, op. cit. note 14, pp. 179-189; Walter et al., op. cit. note 14, pp. 583-594.

${ }^{44}$ A. Kerr. 2004. Genetics and Society: A Sociology of Disease. London and New York: Routledge: 86.

${ }^{45}$ Hallowell, op. cit., note 14, pp, 597-621; McAllister, op. cit. note 14, pp. 179-189; Hallowell et al., note 14. pp.683-691; R. A. Kenen, Arden-Jones and R. Eeles. Family stories and the use of heuristics: women from suspected hereditary breast and ovarian cancer (HBOC) families. Sociology of Health \& Illness 2003; 25(7): 838-865.

${ }^{46}$ Hallowell, op. cit. note 16, pp. 263-275; Hallowell, op. cit. note 16, pp. 597-621; d'AgincourtCanning. op. cit. note 16, pp. 97-118; d'Agincourt-Canning, op. cit. note 16, pp. 231-247.

${ }^{47}$ K. Chalmers and K. Thomson. Coming to terms with the risk of breast cancer: perceptions of women with primary relatives with breast cancer. Qualitative Health Research 1996; 6(2): 256-382.

${ }^{48}$ Kenen, Arden-Jones and Eeles, op. cit. note 45, pp. 838-865; Ibid; Chalmers and Thompson; R. Kenen, A. Ardern-Jones and R. Eeles. Living with chronic risk: healthy women with a family history of breast/ovarian cancer. Health, Risk \& Society 2003; 5(3): 315-331.

${ }^{49}$ M.R. Bury. Chronic illness as biographical disruption. Sociology of Health \& Illness 1982; 4: 167182

${ }^{50}$ Kerr, op. cit., note 44 .

${ }^{51}$ Kenen, Arden-Jones and Eeles, op. cit. note 48, pp. 315-331; U. Beck. 1992. Risk Society: Towards a New Modernity. London: Sage Publications; A. Giddens. 1991. Modernity and Self Identity: Self and Society in the Late Modern Age. Cambridge: Polity Press.

${ }^{52}$ Kenen, Arden-Jones and Eeles, op. cit. note 48, pp. 315-331.

${ }^{53}$ Hallowell, op. cit. note 16, pp. 263-275; N. Hallowell and J. Lawton. Negotiating present and future selves: managing the risks of hereditary ovarian cancer by prophylactic surgery. Health 2002; 6(4): 423-443.

${ }^{54}$ J. S. Polzer, L. Mercer and V. Goel. Blood is thicker than water: genetic testing as citizenship through familial obligation and the management of risk. Critical Public Health 2002; 12(2): 153-168.

${ }^{55}$ Boenick, op. cit. note 16. pp 37-63; G. De Vries and K. Horstman, op. cit. note 16.

${ }^{56}$ Hallowell and Lawton, op. cit. note 53, pp. 423-443; N. Press, J.R. Fishman and B.A. Koenig. Collective fear, individualized risk: the social and cultural context of genetic testing for breast cancer. Nursing Ethics 2007; 7(3): 237-249.

${ }^{57}$ I. Illich. 1976. Medical Nemesis. The Expropriation of Health. New York: Pantheon Books. Lostumbo et al. op. cit. note 4.

${ }^{58}$ Hallowell and Lawton, op. cit. note 53, pp. 423-443.

${ }^{59}$ Calderon-Margalit and Paltiel, op.cit, note 4, pp. 357-364.

${ }^{60}$ Ibid; Calderon-Margalit and Paltiel.

${ }^{61}$ M. Featherstone. The Body in Consumer Society. Theory, Culture and Society 1982; 1(2): p. 18-33. Hallowell, op. cit. note 16, pp. 263-275; C. Shilling. 1993. The Body and Social Theory. London: Sage. ${ }^{62}$ Ibid Featherstone. Ibid; Shilling.

${ }^{63}$ A. Petersen. Risk and the regulated self: the discourse of health promotion as politics of uncertainty. ANZJS 1996; 32(1): 44-57.

${ }^{64}$ G. Ritzer and D. Walczak. 1995. Rationalisation and the deprofessionalisation of physicians. In The Sociology of Medicine. W.C. Cockerham ed. Hants UK. Edward Elgar; D. Lupton. Consumerism, reflexivity and the medical encounter. Social Science \& Medicine 1997; 45(3): 373-381.

65 Ibid; Lupton.

${ }^{66}$ B. Hughes. 2000. Medicalized bodies. In The Body, Culture and Society: An Introduction. P. Hancock et al. eds. Buckingham, Philadelphia. Open University Press: 12-28.

${ }^{67}$ Lupton, op. cit., note 64, pp.373-381.

${ }^{68}$ Calderon-Margalit and Paltiel, op.cit, note 4, pp. 357-364. 
GSP Genomics, Society and Policy

online 2009, Vol.5, No.2 pp.53-66

${ }^{69}$ Boenick, op. cit. note 16 pp 37-63.

${ }^{70}$ C. Novas and N. Rose. Genetic risk and the birth of the individual. Economy and Society 2000; 29(4): 485-513. Page 485.

${ }^{71}$ J. Lawton. Lay experiences of health and illness: past research and future agendas. Sociology of Health \& Illness 2003; 25(3): 23-40.

${ }^{72}$ M. Betta. 2006. From destiny to freedom? On human nature and liberal eugenics in the age of genetic manipulation. In The Moral Social, and Commercial Imperatives of Genetic Testing and Screening.

The Australian Case. Dordrecht/The Netherlands. Springer: 3-24.

Genomics, Society and Policy, Vol.5, No.2 (2009) ISSN: 1746-5354

(C) ESRC Genomics Network. 